\title{
Profiling text comprehension impairments in aphasia
}

Article

Accepted Version

Meteyard, L., Bruce, C., Edmundson, A. and Oakhill, J. (2014) Profiling text comprehension impairments in aphasia. Aphasiology, 29 (1). pp. 1-28. ISSN 1464-5041 doi: https://doi.org/10.1080/02687038.2014.955388 Available at https://centaur.reading.ac.uk/37631/

It is advisable to refer to the publisher's version if you intend to cite from the work. See Guidance on citing.

Published version at: http://www.tandfonline.com/doi/full/10.1080/02687038.2014.955388.

To link to this article DOI: http://dx.doi.org/10.1080/02687038.2014.955388

Publisher: Taylor and Francis

All outputs in CentAUR are protected by Intellectual Property Rights law, including copyright law. Copyright and IPR is retained by the creators or other copyright holders. Terms and conditions for use of this material are defined in the End User Agreement.

\section{www.reading.ac.uk/centaur}

\section{CentAUR}

Central Archive at the University of Reading

Reading's research outputs online 
Meteyard, L., Bruce, C., Edmundson, A., \& Oakhill, J. (2014). Profiling text

comprehension impairments in aphasia. Aphasiology, (ahead-of-print), 1-28.

Profiling text comprehension impairments in aphasia

Lotte Meteyard ${ }^{1}$, Carolyn Bruce ${ }^{2}$, Anne Edmundson ${ }^{2}$, Jane Oakhill ${ }^{3}$

1

Clinical Language Sciences

School of Psychology \& Clinical Language Sciences

Psychology Building

University of Reading

Reading RG6 6AL

United Kingdom

Email: I.meteyard@reading.ac.uk

2

Research Department of Language and Communication

Division of Psychology and Language Sciences

University College London

Chandler House

2 Wakefield Street

London

WC1N 1PF

3

School of Psychology

University of Sussex

Falmer

BN1 9QH 
Meteyard, L., Bruce, C., Edmundson, A., \& Oakhill, J. (2014). Profiling text

comprehension impairments in aphasia. Aphasiology, (ahead-of-print), 1-28.

Key words: acquired dyslexia, aphasia, reading, text comprehension, written comprehension, reading strategies

\section{Abstract}

Background: Research in aphasia has focused on acquired dyslexias at the single word level, with a paucity of assessment techniques and rehabilitation approaches for individuals with difficulty at the text level. A rich literature from research with paediatric populations and healthy non-brain damaged, skilled adult readers allows the component processes that are important for text reading to be defined and more appropriate assessments to be devised.

Aims: To assess the component processes of text reading in a small group of individuals with aphasia who report difficulties reading at the text level. Do assessments of component processes in reading comprehension reveal distinct profiles of text comprehension? To what extent are text comprehension difficulties caused by underlying linguistic and/or cognitive deficits?

Methods \& Procedures: Four individuals with mild aphasia who reported difficulties reading at the text level took part in a case-series study. Published assessments were used to confirm the presence of text comprehension impairment. Participants completed a range of assessments to provide a profile of their linguistic and cognitive skills, focusing on processes known to be important for text comprehension. We identified the following areas for assessment: reading speed, language skills (single word and sentence), inferencing, working memory and metacognitive skills (monitoring and strategy use).

Outcomes \& Results: Performance was compared against age-matched adult control data. One participant presented with a trend for impaired abilities in inferencing, with all other assessed skills being within normal limits. The other three had identified linguistic and working memory difficulties. One presented with a residual deficit in accessing single word meaning that affected text comprehension. The other two 
Meteyard, L., Bruce, C., Edmundson, A., \& Oakhill, J. (2014). Profiling text

comprehension impairments in aphasia. Aphasiology, (ahead-of-print), 1-28.

showed no clear link between sentence processing difficulties and text

comprehension impairments. Across these three, data suggested a link between

verbal working memory capacity and specific inferencing skills.

Conclusions: Successful text reading relies on a number of component processes.

In this paper we have made a start in defining those component processes and devising tasks suitable to assess them. From our results, assessment of verbal working memory and inferencing appears to be critical for understanding text comprehension impairments in aphasia. It is possible that rehabilitation input can capitalize on key meta-cognitive skills (monitoring, strategy use) to support functional reading in the face of existing linguistic, text comprehension and memory impairments. 
Meteyard, L., Bruce, C., Edmundson, A., \& Oakhill, J. (2014). Profiling text

comprehension impairments in aphasia. Aphasiology, (ahead-of-print), 1-28.

Introduction

For the majority of adults, reading is a skill that is part of everyday life. A skilled reader is one that can read large chunks of text (a novel, a newspaper, a report) with speed and fluency whilst maintaining comprehension. The ability to read is essential for many adults and literacy is used as a variable in population measures of quality of life (Slottje, 1991). For individuals with aphasia (impairments to language and communication following neurological damage) difficulties comprehending paragraphs and longer texts, despite the capability to read and understand single words, can be a frustrating part of their aphasic profile (Coelho, 2005; Kim \& Russo, 2010). Difficulties reading and comprehending text present more frequently than difficulties decoding single words (Breznitz, Shaul, Horowitz-Kraus, Sela, \& Karni, 2013; Webb \& Love, 1983) and can lead to social exclusion and work problems; literacy and reading comprehension have been identified as key factors in successful return to work (Penn \& Jones, 2000). They are most often part of a mild aphasic profile (Coelho, 2005; Rogalsky \& Edmonds, 2008; Sinotte \& Coelho, 2007). The majority of research on adult acquired reading disorders focuses on assessment and remediation at the single word level (Cherney, 2004; Funnell, 2000; Kim \& Russo, 2010), which is less applicable to those with text level difficulties (Kim \& Russo, 2010). At the present time, there are few options for assessing text level reading (Ellmo, Graser, Krchnavek, Hauck, \& Calabrese, 1995; LaPointe \& Horner, 1998) and available assessments "provide limited direction regarding treatment; they give limited insight into the nature of the underlying difficulty or what strategies are likely to be beneficial" (Webster et al, 2013, page 1374). A concise review of existing therapy approaches is given in Webster et al (2013), which also adds to the growing set of case-studies on remediation of text comprehension impairments in aphasia (Coelho, 2005; Cocks et al, 2013; Lynch et al, 2009; Meteyard, Bruce, Edmundson \& Ayre, 2010; Potts \& Morris, 2010; Rogalsky \& Edmonds, 2008; Sinotte \& Coelho, 
Meteyard, L., Bruce, C., Edmundson, A., \& Oakhill, J. (2014). Profiling text comprehension impairments in aphasia. Aphasiology, (ahead-of-print), 1-28. 2007). Here we focus on assessment, and what tasks and approaches can be used to better understand the nature of text comprehension impairments in aphasia.

In skilled reading all steps of the reading process are relatively automatic and do not require significant effort; difficulties with reading can be signaled by reading that is excessively slow or not fluent (Wimmer, Mayringer, \& Landerl, 1998) and this can be a key complaint of adults with acquired text comprehension difficulties (Meteyard, Bruce, Edmundson, \& Ayre, 2010). Text comprehension is complex. Neuroimaging with healthy adults has shown that text reading engages not only 'typical' lefthemisphere language regions (e.g. the inferior frontal gyrus, middle and superior temporal gyri, anterior temporal lobe) but also right hemisphere homologues of these areas (Ferstl, Neumann, Bogler \& Von Cramon, 2008). In individuals with traumatic brain injury ( $\mathrm{TBI})$, lesions to a broad network of fronto-parietal regions correlate with discourse comprehension impairments and are strikingly similar to lesion-symptom maps for executive function impairments (Barbey, Colom \& Grafman, 2014). As yet, no lesion studies exist for text comprehension deficits in aphasia post-stroke.

Literature on the typical development of reading and skilled adult readers has defined some key processes for successful text comprehension. These processes have been separated into lower level skills related to single word decoding, and higher level skills related to constructing the meaning of the text (Cain et al., 2004; Landi, 2010; Oakhill, Hartt, \& Samols, 2005; Snow, 2002). It has been argued that assessments of reading must take into account these component processes (Cain, Oakhill, \& Bryant, 2004; Guo, Roehrig, \& Williams, 2011; Hannon, 2012; McBride Chang, 2004; Mokhtari \& Reichard, 2002).

A useful framework for understanding text level reading is given by Perfetti (2000), who separates reading into three broad stages. First are visual processes that are critical to get information but not counted as part of cognitive-linguistic processing. 
Meteyard, L., Bruce, C., Edmundson, A., \& Oakhill, J. (2014). Profiling text comprehension impairments in aphasia. Aphasiology, (ahead-of-print), 1-28.

These can be disrupted by visual defects (e.g. oculo-motor control deficits, hemianopia, damage to visual processing regions of the brain) and can result in acquired peripheral alexias (e.g. hemianopic alexia; Leff, Spitsyna, Plant \& Wise, 2006). Second are processes that involve the decoding and recognition of orthography, accessing lexical representations and thus the linguistic knowledge available to the reader (e.g. semantics, morphology, syntax; Perfetti, 2000). Acquired central alexias manifest at this level, with pure alexia representing the border between visual processes and lexical representations (Cherney, 2004; Leff et al, 2006). Other acquired alexias that affect single word reading have been categorized, e.g. surface alexia (difficulty with irregular orthography-phonology mappings), phonological alexia (difficulty with unfamiliar/novel words) and deep alexia (semantic errors; Cherney, 2004; Crisp \& Lambon-Ralph, 2006). At the text level, knowledge of and access to vocabulary, morphology and syntax make a significant contribution to reading comprehension in adult readers (Guo et al., 2011; Long \& Chong, 2001). These linguistic skills are amongst those we know to be impaired in aphasia (Kertesz, 1982) and it is likely that text comprehension impairments for some individuals with aphasia will be caused or exacerbated by underlying linguistic deficits. Thirdly, there are more general cognitive skills that operate over linguistic skills, and allow the reader to construct the meaning of what is being read (Perfetti, 2000). These will now be discussed in more detail.

It is hypothesized that readers represent the text both as propositions (i.e. founded on the original sentence structure, as a 'text base'; Perfetti, 2000) and as more developed situation models (van Dijk \& Kintsch, 1983). Asking participants questions about what has been stated in the text is one way of to assess the text base representation. A task that does not require a spoken response is sentence verification. Here, participants read a passage and then decide whether sentences that paraphrase the original meaning were present in what they read (making an 
Meteyard, L., Bruce, C., Edmundson, A., \& Oakhill, J. (2014). Profiling text comprehension impairments in aphasia. Aphasiology, (ahead-of-print), 1-28. old/new, or true/false judgment; Royer, 1979; Sohlberg, Griffiths \& Fickas; 2014). If the shallow text-base meaning has been extracted, paraphrase sentences should be accepted as 'old' or 'true'. The situation model is built by combining what is read with prior knowledge about the world to establish the 'scene' or context that is described (Fincher-Kiefer, 2001; Rinck \& Bower, 2000; Rinck, Hahnel, Bower, \& Glowalla, 1997; van Dijk \& Kintsch, 1983; Zwaan, 1999; Zwaan \& B.H.Ross, 2004; Zwaan \& Radvansky, 1998). The relationship between these two representations has been clearly stated by Perfetti (2000, page 188): "Text bases... [contain] meaning representations generated with minimal inferencing... perhaps only those inferences needed to maintain referential coherence. Situation models, by contrast, are semantically deep, containing situation-specific meanings that generate rich inferences". Thus, inference skills are key in extracting meaning from text (Long \& Chong, 2001) and it is debated whether they are automatically generated by skilled adult readers (Graesser, Singer, \& Trabasso, 1994; Perfetti, 2000). There are multiple ways of classifying inferences, so for simplicity we will make a broad distinction between local and global. Local inferences allow referential coherence, that is, they make sense of the text by linking successive elements (e.g. words, clauses, premises) that are read (Cain, Oakhill, Barnes \& Bryant, 2001). Global inferences draw on background knowledge to elaborate and enrich the situation model (Cain et al, 2001; Perfetti, 2000). Text comprehension difficulties may therefore arise through deficits in higher-level processes, for example in how inferences (local and global) are established. Specific difficulties with inferencing have been observed in TBI. For example, in making judgments about how two sentences pragmatically link together (Ferstl, Guthke \& von Cramon, 2002) or in identifying which implied statements link to a previously read text (Sohlberg, Griffiths \& Fickas; 2014).

The maintenance of information is critical for these higher-level aspects of reading. 
Meteyard, L., Bruce, C., Edmundson, A., \& Oakhill, J. (2014). Profiling text comprehension impairments in aphasia. Aphasiology, (ahead-of-print), 1-28.

Working memory, as measured by complex working memory span, is a key mediator in reading comprehension ability (e.g. Carretti, Borella, Cornoldi, \& De Beni, 2009; Hannon, 2012; McVay \& Kane, 2012). Reduced working memory capacity has been found to contribute to text comprehension difficulties in aphasia (Mayer \& Murray, 2012) and discourse comprehension (across spoken and written modalities) for individuals with traumatic brain injury is highly predicted by working memory capacity (Barbey, Colom \& Grafman, 2014). Working memory is not just about storage capacity, indeed, research with healthy adult readers suggests that for text comprehension, the important factor is the ability to allocate attention and control relevant information at any one moment (McVay and Kane, 2012). Impairments in working memory may therefore interact with linguistic deficits (Caplan, Michaud, \& Hufford, 2013). For example, difficulty in retrieving relevant information via lexical or syntactic processes will be further compounded by difficulties in deploying that information to build a rich representation of the text (i.e. the situation model).

An additional part of successful reading is the ability to apply meta-cognitive strategies to support reading comprehension (Kletzien, 1991). Knowledge about one's own cognitive processes, or 'thinking about thinking', allows individuals to plan a reading activity and adjust the way they read different texts (e.g. a text-book versus a novel). These skills are important in being able to monitor comprehension, detect errors and resolve problems when something is not understood (Erhlich, Redmond, \& Tardieu, 1999; Mokhtari \& Reichard, 2002; Oakhill et al., 2005; Schreiber, 2005). A study with 3 individuals with aphasia found that they used strategies to increase the efficiency (speed and accuracy) of reading, to bring their background knowledge to bear more effectively (e.g. focusing on the meaning) and to overcome comprehension difficulties (e.g. using a dictionary) (Lynch, Damico, Abendroth \& Nelson, 2013). Crucially for aphasia rehabilitation, meta-cognitive strategies can be used to improve text comprehension (Cocks et al, 20130; Coelho, 2005; Meteyard et 
Meteyard, L., Bruce, C., Edmundson, A., \& Oakhill, J. (2014). Profiling text

comprehension impairments in aphasia. Aphasiology, (ahead-of-print), 1-28.

al., 2010; Rogalsky \& Edmonds, 2008; Sinotte \& Coelho, 2007; Webster et al, 2013).

In sum, text comprehension depends on multiple cognitive processes. Based on the

existing literature, we have highlighted reading speed, language skills, representation of the text base, inferencing (local and global), working memory and meta-cognitive skills. These elements are known to be important either as key contributors to successful reading or as part of the text comprehension process itself. More importantly, they represent a set of variables that can provide an overall profile of an individual's text comprehension skills.

In this paper, we present a case-series analysis of four individuals with acquired text comprehension impairments post-stroke. The aim is to build profiles of text reading for different individuals. In doing so, we move towards targeting skills for assessment and for rehabilitation (Webster et al, 2013). One hypothesis is that there will be a clear link between particular linguistic deficits (e.g. access to word meaning, difficulties parsing sentences) and difficulties in text comprehension. Alternatively, complex skills that we know to be key for successful text comprehension (e.g. inferencing, working memory) may show deficits that are separable from underlying linguistic performance. This second outcome would argue for assessment of these more complex skills being vital for the targeting of rehabilitation approaches.

Method

\section{Participants}

Four participants with chronic aphasia following left-hemisphere stroke (1 male, 3 female) were recruited from a University research panel and aphasia communication support groups. Participants were recruited on the basis of reporting adequate 
Meteyard, L., Bruce, C., Edmundson, A., \& Oakhill, J. (2014). Profiling text comprehension impairments in aphasia. Aphasiology, (ahead-of-print), 1-28. reading of single words and sentences, but difficulty reading text. This profile was then confirmed with initial testing (see below). The average age was 64 years (SD 11.2) and average time post stroke was 4 years (range 3 to 5 ) at the time of testing. All were right handed prior to their stroke. See Table 1 for demographic details, aphasia classification and severity based on the Western Aphasia Battery (WAB; Kertesz, 1982) and details of stroke lateralisation (from medical referral information). All participants had normal or corrected to normal vision and hearing, and no other neurological or psychiatric conditions. Healthy older adults (five male, three female) were recruited via convenience sampling to provide age and education matched control data for further assessments of skills relevant to text reading. Their average age was 62.6 years (SD 9.2). Control data was collected by different researchers, resulting in some assessments being completed by only a subset of controls. All eight completed the written synonyms test (Psycholinguistic Assessments of Language Processing in Aphasia, PALPA, subtest 50; Kay, Lesser \& Coltheart, 1992), verbal working memory test (PALPA subtest 60), and long error detection / comprehension monitoring task. Seven completed the inferencing test (local and global) and sentence verification; average age 64.4 years, SD 8.3) and five completed the short error detection and reading speed assessment (average age 60.6 years, SD 6.2). See below for details of these assessments. Where control data was sufficient ( $\mathrm{n}$, mean and standard deviation values) patient data was compared against controls using procedures outlined in Crawford et al $(1998,2002,2010)$.

These analyses make it possible to use data from small control samples. Otherwise, performance was defined as impaired when it was below and outside the minimum of the normal range; for example, on the Measure of Cognitive Linguistic Ability (MCLA; Ellmo et al, 1995) in which the sample size for each age-group is not provided. Control data is not provided for the RCBA. 
Meteyard, L., Bruce, C., Edmundson, A., \& Oakhill, J. (2014). Profiling text

comprehension impairments in aphasia. Aphasiology, (ahead-of-print), 1-28.

Informed consent was obtained in writing from all participants. Aphasia friendly

information and consent forms were used for the participants with aphasia.

Table 1: Demographic information and aphasia profile

Key:

${ }^{1} \mathrm{~L}$ - Left hemisphere

2 Handedness pre stroke, $\mathrm{R}$ - right handed

${ }^{3} \mathrm{Bi}$ - Bilingual, Mono - monolingual

${ }^{4}$ Aphasia Quotient scores $>76$ are classed as mild and $>93.5$ as resolved.

\begin{tabular}{|c|c|c|c|c|c|c|c|}
\hline PT ID & Age & Sex & $\begin{array}{l}\text { CVA } \\
\text { hemisphere } \\
\text { and year }{ }^{1}\end{array}$ & Hand $^{2}$ & Language $^{3}$ & 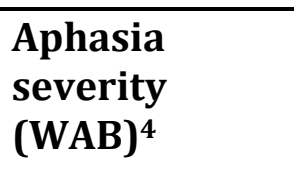 & $\begin{array}{l}\text { Aphasia } \\
\text { classification } \\
\text { (WAB) }\end{array}$ \\
\hline $\mathbf{W}$ & 79 & $\mathrm{~F}$ & $L, 2009$ & $\mathrm{R}$ & Bi (Italian) & 94, resolved & Anomic \\
\hline $\mathbf{L}$ & 64 & $\mathrm{M}$ & L, 2009 & $\mathrm{R}$ & Mono & 92, mild & Anomic \\
\hline $\mathbf{S}$ & 52 & $\mathrm{~F}$ & L, 2008 & $\mathrm{R}$ & Mono & 82.4, mild & Conduction \\
\hline $\mathbf{P}$ & 61 & $\mathrm{~F}$ & L, 2007 & $\mathrm{R}$ & Mono & $\begin{array}{l}74.6, \\
\text { mild/moderate }\end{array}$ & Broca's \\
\hline
\end{tabular}

\section{Case histories}

W

W is a 79-year-old, bilingual, right-handed female who had a left sided

cerebrovascular accident (CVA) 3 years 4 months prior to testing. W was in full time

education for 15 years and came to the UK from Italy as a teenager. As well as speaking Italian and English fluently, W speaks Greek and understands Spanish.

Prior to W's CVA she was retired having previously run her own business. For selfrating of reading confidence (a $10 \mathrm{~cm}$ visual analogue scale), she reported $100 \%$ confidence when reading headlines and $72 \%$ for longer texts. She reported always being able to read single words and sentences, being able to read a piece in the newspaper most of the time and a book slowly. 
Meteyard, L., Bruce, C., Edmundson, A., \& Oakhill, J. (2014). Profiling text

comprehension impairments in aphasia. Aphasiology, (ahead-of-print), 1-28.

$\mathbf{L}$

$\mathrm{L}$ is a 64-year-old, right-handed, monolingual male who had a left sided CVA 3 years

1 month prior to testing. $L$ was in full time education for 21 years, studying up to a doctoral level. Prior to the CVA, he was retired from a career as public servant. For self-rating of reading confidence, $L$ reported $72 \%$ confidence when reading headlines and $42 \%$ confidence with longer texts. He reported always being able to read single words and sentences, being able to read a piece in the newspaper most of the time and a book slowly.

\section{S}

$S$ is a 52-year-old, right-handed, monolingual female, who had a left sided CVA 4 years 4 months prior to testing. SC was in full time education for 16 years, up to undergraduate degree level. Prior to the CVA, she was working full time as director in a middle sized company. She returned to work for two years post CVA but left again in 2010 due to her aphasia. For self-ratings of reading confidence, she reported $87 \%$ confidence for headlines and sentences, and $49 \%$ confidence for longer texts. She reported always being able to read single words and sentences, being able to read a piece in the newspaper most of the time and not being able to read books.

\section{$\mathbf{P}$}

$P$ is a 61-year-old, monolingual, right-handed woman who had a left-sided CVA 4 years 11 months prior to testing. $\mathrm{P}$ was in full time education for 17 years up to Master's level. Prior to her CVA, she worked as a head teacher. She retired following the stroke. For VAS ratings of reading confidence, she reported $80 \%$ confidence when reading headlines, and $10 \%$ confidence with longer texts. She reported being able to read single words, sentences and a piece in the newspaper most of the time and not being able to read books. 
Meteyard, L., Bruce, C., Edmundson, A., \& Oakhill, J. (2014). Profiling text

comprehension impairments in aphasia. Aphasiology, (ahead-of-print), 1-28.

\section{Design}

A cross sectional, case-series observational design was used. For assessment tasks that were created for the purpose of this study, we compared patient data against the age matched control group.

\section{Materials}

\section{Identifying a text comprehension impairment}

Two available formal assessments were used to evaluate the presence of a text comprehension impairment. The Reading Comprehension Battery for Aphasia (RCBA; LaPointe and Horner, 1998) is currently the only existing battery aimed solely at assessing reading skills in aphasia. The battery has 10 core subtests and 7 supplemental subtests. Core subtests assess synonym judgment, single word, sentence and short paragraph comprehension; morpho-syntactic reading; functional reading (e.g. menus / food packets); factual and inferential comprehension for short paragraphs. Supplemental subtests assess lower level decoding skills (letter discrimination, naming and recognition), lexical decision, semantic categorization and oral reading (single words and sentences). We also used reading subtests from the MCLA. This is designed for clients who have mild-moderate impairments caused by traumatic brain injury. The reading subtests are functional reading (a newspaper extract, cleaning product label/instructions and a menu; questions targeting details stated explicitly and implied information), factual reading (one page, questions targeting details stated explicitly in the text) and inferential reading (questions targeting details stated explicitly and implied information). In both the RCBA and MCLA, the individual is allowed to refer back to the text while answering the questions. However, there is a considerable difference in the length of the passages in the two assessments. The RCBA's longest paragraph is 52 words, compared to the MCLA's that are 370, 444 and 614 words long. Based on these assessments, a text comprehension impairment is indicated when performance is at or near ceiling 
Meteyard, L., Bruce, C., Edmundson, A., \& Oakhill, J. (2014). Profiling text

comprehension impairments in aphasia. Aphasiology, (ahead-of-print), 1-28.

on the RCBA core subtests (i.e. relatively intact single word and sentence reading) and below the minimum of the normal range based on the older adult group control for the MCLA.

\section{Reading Speed}

The passages in the MCLA factual and inferential subtests were used as representative longer texts. For individuals with aphasia, the time taken to complete the first silent reading of each MCLA passage was recorded. For control participants, the time taken to silently read the passages was recorded. For both, words per minute reading speed was calculated (number of words / time taken in seconds, multiplied by 60 ) and averaged across the three passages.

\section{Language Performance}

Single word comprehension / access to vocabulary

Subtests from the PALPA (Kay, Lesser \& Coltheart, 1992) were used. Specifically, spoken-word to picture matching (Subtest 47) and written-word to picture matching (Subtest 48) provided a measure of access to vocabulary. Scores represent total number correct and control data is taken from that available in the PALPA. A harder task, written synonym judgment (Subtest 50 ), was used to test retrieval of more finegrained lexico-semantic information for written words. Scores represent total number correct and control data was provided by our control sample (none provided in PALPA).

\section{Sentence Comprehension / syntactic knowledge}

Two sentence comprehension tasks were used, a spoken and a written sentence to picture matching task (PALPA Subtest 55 and Subtest 56). Sentences include reversible and non-reversible structures and structures with increased complexity 
Meteyard, L., Bruce, C., Edmundson, A., \& Oakhill, J. (2014). Profiling text

comprehension impairments in aphasia. Aphasiology, (ahead-of-print), 1-28.

(e.g. passives). Scores represent total number correct on each sentence type and control data is taken from that available in the PALPA.

\section{Inferencing: Local and Global}

Local inferences require the reader to make links between successive words and sentences in the text whereas global inferences involve the integration of world knowledge. Local inferences can be targeted by questions whose answers require successive words and clauses to be linked. Global inferences are targeted by questions whose answers require the integration of world knowledge (Cain \& Oakhill, 2011). To target local and global processes specifically we adapted an inference task used in paediatric research (Cain \& Oakhill, 2011). Five short stories were created, intended to be easily read and understood by an adult (mean words $=119$, range 76-141; Flesch Reading Ease mean $=82.5$, range 74-90.5; average reading age $=11$ years, range 10-13). Longer passages were not always more difficult (two shortest passages $=76$ and 117 words, reading age $=13$ and 12 years; two longest passages $=139$ and 141 words, reading age for each $=10$ years). Each story had four questions (see Appendix 1 A). Two questions required the linking of successive words (local) and two required the integration of world knowledge (global). Participants were not allowed to refer back to the stories when answering. Stories were piloted with a small group of non-brain damaged adult readers who were asked to judge whether questions targeted these aspects separately. For local inferences, they were asked to decide whether questions could be answered by linking information stated in the text. For global inferences, they were asked to decide whether questions needed knowledge not mentioned in the passage to be used. To get a more complete picture of the participants inferencing ability we also used data from the MCLA to compare factual versus inferential reading, with the caveat that individuals can refer back to the text when answering. Errors for these tasks were categorized thematically into the following bins: omission (no response), partial (part 
Meteyard, L., Bruce, C., Edmundson, A., \& Oakhill, J. (2014). Profiling text

comprehension impairments in aphasia. Aphasiology, (ahead-of-print), 1-28.

of the correct answer), missed (wrong information used from the text, missing the correct answer), wrong (wrong answer, not taken from the text), quote (a direct quote from the text), other (vague answers, misread the question, needed prompts). See Appendix $1 \mathrm{~B}$ for details and examples.

\section{Representing the text base}

To look at the representation of the text base, we used a sentence verification paradigm taken from Royer (1979) (see Appendix 1 C). Participants read a passage silently before being presented with a series of 15 sentences. Participants were asked to say whether the sentences were the same as sentences they had just read by indicating whether it was 'old' (same) or 'new' (different). Participants were not allowed to look back at the passage. Four different sentences types were presented. Original sentences and paraphrased sentences (meaning retained but surface structure altered) should have been classed as 'old'. Meaning change items (sentence structure retained with individual words changed, e.g. 'mother' to 'father') and distracter sentences (unrelated to original story but with the same characters) should have been classed as 'new'. In this task, normal performance is seen when paraphrase items are accepted as 'old', but meaning change items are not. This shows that the overall meaning of the text has been retained over and above specific sentences (Royer, 1979). A total correct score out of 15 is provided.

\section{Working Memory}

To avoid using a measure of verbal working memory that is confounded by speech production difficulties, we used the pointing span subtest from PALPA (subtest 60; Kay, Lesser \& Coltheart, 1992) and modified it to measure both forward and backward span (i.e. pointing to pictures in the presented order, or reversing the order of presentation). This task mirrors forward and backward span in digit or word string recall tasks. Backward span is taken as a better measure of working memory as it 
Meteyard, L., Bruce, C., Edmundson, A., \& Oakhill, J. (2014). Profiling text comprehension impairments in aphasia. Aphasiology, (ahead-of-print), 1-28. requires both storage and manipulation of information (Lee Swanson, Howard, \& Saez, 2006). Participants were verbally presented with sequences of words and required to point to corresponding pictures of objects and actions in the same sequence as the words they heard. Comprehension of the individual words is checked before the test is administered (single word to picture matching). The sequence length increases from two to six. Pictures are ordered into subject verb pairs and subject verb object triplets (e.g. span 2 SV: 'mouse write', span 3 SVO: 'mouse write hat', span 4 SV SV: 'hat write, mouse cut'). There are two trials for each sequence length up to five and four trials for the final length of six (12 trials in total). Testing stops after two consecutive failures. Scores are given for the number of correct trials successfully completed.

\section{Meta-Cognitive skills: error detection}

Easy and hard error detection tasks were created. For the easy version, an anomaly detection task was adapted from Oakhill, Hartt and Samols (2005) (see Appendix 1 D). There were six test passages, made up of 6 sentences presented in a list. Four of the passages included two inconsistent sentences; in two of the passages the inconsistent information appeared in adjacent sentences, in the other two the inconsistent information was presented several sentences apart. The remaining two passages did not contain inconsistent information. Participants were instructed to underline any anomalies they came across. Post reading, participants were asked to indicate whether the passage made sense or not. A second, harder, error detection task with longer passages was adapted from Cain \& Oakhill (2011). Seven passages were created (mean words $=88$, range 59-113; Flesch Reading Ease mean $=70.0$, range 59-79; average reading age $=13.7$ years, range 12-16). Longer passages were not always more difficult (e.g. two shortest passages $=59$ and 75 words, reading age $=15$ and 16 ; two longest passages $=106$ and 113 words, reading age $=13$ and 12 ). Four of these contained sentences that contradicted each 
Meteyard, L., Bruce, C., Edmundson, A., \& Oakhill, J. (2014). Profiling text

comprehension impairments in aphasia. Aphasiology, (ahead-of-print), 1-28.

other, and three contained no contradictions. Contradictory sentences were adjacent (one text), separated by one intervening sentence (two texts) or two intervening sentences (one text). Participants were asked to read through the stories, decide if they made sense, and identify parts that did not make sense (i.e. the two sentences that contradicted each other). Therefore, the error detection tasks were similar with difficulty increased by the longer passages in the second task. Scores report the total number of errors correctly identified. Reponses for these tasks were also classed into correct identifications (a contradiction correctly identified) and false positives (consistent parts misidentified as errors).

Meta-cognitive strategies: self-report of reading strategies

Participants completed the Metacognitive Awareness of Reading Strategies Inventory (MARSI, Mokhtari \& Reichard, 2002). Originally designed for academic/educational contexts, it contains 30 questions answered with a 5 point Likert scale ( $1=$ never, 5 = always). Questions are scored on 3 subscales: Global reading strategies, Problem-Solving Strategies and Support Reading Strategies. Global strategies relate to taking an overall analysis of a text, e.g. "I have a purpose in mind when I read". Problem solving strategies relate to actions taken when the text becomes difficult to read, e.g. "I adjust my reading speed according to what I read". Support reading strategies relate to using practical strategies to support reading, e.g. "I take notes whilst reading". It was presented in written form with the researcher reading each question aloud to support comprehension. High scores indicate that a particular strategy group is used frequently.

\section{Procedure}

All testing took place in a quiet environment at the participant's home, with regular breaks, and no session lasted longer than two hours. Number of sessions varied between the participants, with the average number of sessions being 4.5 . In all 
Meteyard, L., Bruce, C., Edmundson, A., \& Oakhill, J. (2014). Profiling text

comprehension impairments in aphasia. Aphasiology, (ahead-of-print), 1-28.

cases the WAB, RCBA and MCLA were administered first, with the order of

remaining tasks being counterbalanced across participants.

\section{Results}

Table 2 presents data for background assessments of reading for all participants.

Following guidelines from Crawford et al (2010) further assessment data is presented with one table per participant (Tables 3-6). Where control data was sufficient, this also shows whether performance is significantly different to controls. Table 7 presents the data from the MARSI questionnaires across all participants (self-report of reading strategy use). Data for response and error types by task are presented in Appendix 2.

\section{Table 2: Background reading assessment}

Key: NR - normal range

Grey shading indicates a score below the normal range. Control data is not available for the RCBA. Grey shading indicates a score below the normal range (NR) on the MCLA. Control data is not available for the RCBA. See Appendix 2 Table 1 for a breakdown of errors

\begin{tabular}{llllll}
\hline PT ID & $\begin{array}{l}\text { Reading Comprehension } \\
\text { Battery for Aphasia } \\
(\mathrm{RCBA})\end{array}$ & $\begin{array}{l}\text { Measure of cognitive linguistic } \\
\text { abilities (MCLA) - reading subtests }\end{array}$ \\
\cline { 2 - 6 } & $\begin{array}{l}\text { Core } \\
(/ 100)\end{array}$ & $\begin{array}{l}\text { Supplemental } \\
(/ 100)\end{array}$ & $\begin{array}{l}\text { Functional } \\
\text { NR: } 26-30\end{array}$ & $\begin{array}{l}\text { Factual } \\
\text { NR: 17-20 }\end{array}$ & $\begin{array}{l}\text { Inferences } \\
\text { NR: 28-38 }\end{array}$ \\
\hline W & $93^{1}$ & 100 & 24 & 20 & 22 \\
L & $90^{2}$ & 99 & 19 & 20 & 19 \\
S & $92^{3}$ & $95^{3}$ & 26 & 14 & 29 \\
P & $93^{4}$ & $76^{4}$ & 8 & 8 & 19 \\
\hline
\end{tabular}


Meteyard, L., Bruce, C., Edmundson, A., \& Oakhill, J. (2014). Profiling text

comprehension impairments in aphasia. Aphasiology, (ahead-of-print), 1-28.

\section{Background assessments of reading}

On the core RCBA subtests (Table 2), all individuals scored 90 or above out of a maximum score of 100 . All individuals showed errors in tasks requiring the reading of short paragraphs (paragraph picture and/or paragraph inferential subtests), as well as errors in the morpho-syntax subtest (Appendix 2, Table 1). On Supplemental subtests, $W$ and $L$ scored at or near ceiling. $P$ and $S$ had low scores on tests requiring oral reading, reflecting their speech production difficulties (Appendix 2, Table 1). For the MCLA reading subtests, $W$ and $L$ scored below the normal range for functional and inferential reading. $S$ scored below the normal range for factual reading only and $\mathrm{P}$ scored below the normal range for all subtests, with substantially lower scores than $\mathrm{W}, \mathrm{L}$ and $\mathrm{P}$ on functional and factual subtests (Table 2). Error analysis from the MCLA is described below as part of the Inferencing section.

\section{Language performance}

For all participants, written word comprehension was within the normal range (Tables 3-6). When tested with a more challenging task (written synonym judgment), L scored significantly worse than controls (Table 4). For W, spoken and written sentence comprehension was in the normal range (Table 3). Written sentence comprehension was in the normal range for L. His spoken sentence comprehension was in the normal range for all sentences except 'converse relations', on which he showed impaired performance (Table 4). For S, spoken sentence comprehension was impaired across all types and written sentence comprehension was impaired for reversible and gap as subject sentences (Table 5). For $P$, impairments were apparent in both spoken and written modalities, but for different types (Table 6). Nonreversible sentences were impaired only for spoken comprehension. There was evidence that syntactic difficulties were worse for written comprehension. Reversible sentences were below the $10^{\text {th }}$ percentile in both modalities, but significantly impaired 
Meteyard, L., Bruce, C., Edmundson, A., \& Oakhill, J. (2014). Profiling text

comprehension impairments in aphasia. Aphasiology, (ahead-of-print), 1-28.

for written sentences. Gapped sentences were impaired in both modalities, but more consistently impaired (both gap types) for written comprehension (Table 6).

Across all patients there was a divergence between performance on the RCBA, where individuals achieved comparable overall scores on core tests (90 to 93) and found similar subtests difficult and performance on the MCLA where performance was more variable. For the individuals with mild/resolved aphasia (W and L), both were within normal limits for spoken and written single word to picture matching. W was also within normal limits for sentence comprehension. L's performance on written synonym judgment indicated a residual impairment in accessing the meaning of written words. This was supported by his performance on spoken comprehension of 'converse relation' sentences, in which verbs with contrasting agent-patient roles are used (e.g. buy-sell). In these items the roles are lexicalized rather than signaled by a structure (as in a passive) and problems with these items show difficulties with verb meaning (e.g. Jensen, 2000). Both $W$ and $L$ performed worse than controls on functional and inferential reading in the MCLA.

For the two individuals with more severe aphasia, there was evidence of verbal working memory problems. S had written and spoken sentence comprehension impairments. She was impaired across all spoken sentence types, indicating an impact of verbal working memory. She performed within normal limits for functional and inferential reading but below the controls for factual reading in the MCLA. P had sentence comprehension difficulties in both modalities. She was impaired on nonreversible sentences in the spoken modality, indicating an effect of verbal working memory here. Performance across other sentence types indicated a central syntactic deficit (in line with her classification as a Broca's aphasic). She performed below normal limits on all three reading subtests of the MCLA. 
Meteyard, L., Bruce, C., Edmundson, A., \& Oakhill, J. (2014). Profiling text

comprehension impairments in aphasia. Aphasiology, (ahead-of-print), 1-28.

For three out of four participants, silent reading speed was below the average for control participants $\left(10-20^{\text {th }}\right.$ percentile for $\mathrm{W}, \mathrm{S}$ and $\mathrm{P}$; Table $\left.3,5 \& 6\right)$. In contrast to other participants, $L$ had a faster reading speed of $410 \mathrm{wpm}$ (above $75^{\text {th }}$ percentile, Table 4).

------- See end of document for Tables 3-6

\section{Key for Tables (3-6)}

*one-tailed probability. Grey shading indicates the participant's score is significantly below control data (Sig test) or below and outside the normal range (participant's score, e.g. 'W's score'). Spoken words = spoken word to picture matching (PALPA 47), Written words $=$ written word to picture matching (PALPA 48), Spoken sentences $=$ spoken sentence to picture matching (PALPA 55), Written sentences $=$ written sentence to picture matching (PALPA 56), VWM = verbal working memory.

\section{Inferencing}

In the MCLA subtests (long passages that could be referred back to when answering questions), W was below the normal range on inferential reading but not factual reading (Table 2). When local and global inferences were targeted specifically, $\mathrm{W}$ was below the normal range and performed similarly for both (Table 3 ). $\mathrm{L}$ also scored below the normal range on inferential but not factual reading in the MCLA (when he could refer back; Table 2) but was worse on global inferences than local inferences (Table 4). S was below the normal range for factual reading but not inferential in the MCLA (Table 2) and also showed worse performance on global versus local inferencing (Table 5). Therefore, S performs well in making inferences when she can check the text (MCLA), but otherwise struggles to integrate world knowledge whilst reading. Finally, $\mathrm{P}$ was below the normal range for both factual and inferential reading in the MCLA, with worse performance on functional and factual subtests (Table 2). Her performance was poorer on global than local inferencing (Table 6). 
Meteyard, L., Bruce, C., Edmundson, A., \& Oakhill, J. (2014). Profiling text

comprehension impairments in aphasia. Aphasiology, (ahead-of-print), 1-28.

Similar to S, this shows a difficulty integrating knowledge whilst reading. Overall, three out of four participants ( $L, S$ and $\mathrm{P}$ ) showed worse performance on global than local inferencing (Tables 4-6).

For functional and factual subtests in the MCLA, errors tended to be direct quotes from the text (6/25 errors), information taken from the text but incorrect ('missed' category; 6/25 errors), wrong answers not taken from the text (4/25 errors) and partially correct responses (4/25 errors). For the inferential subtests, participants tended to not provide a response ('omission', 10/40 errors), give partially correct responses (9/40 errors), wrong answers not taken from the text (7/40 errors) and quotes from the text (7/40 errors). See Appendix 2 Table 1 for a full breakdown of errors. The majority error type made for global inferences were incorrect quotes from the text (9/19 errors). See Appendix 2 Table 2 for a full breakdown of errors.

\section{Representing the text base}

Participant $\mathrm{W}, \mathrm{S}$ and $\mathrm{P}$ were within normal limits for the sentence verification task (Tables 3, 5 \& 6). L was the only one worse than controls on this task (Table 4); his responses showed a tendency to not recognise original sentences and to accept meaning change sentences as 'old'; this indicates difficulty in building a stable representation of the text base. See Appendix 2 Table 3 for a full breakdown of responses.

\section{Working Memory}

Impairments in forward and backward picture pointing span (verbal working memory. VWM) mirror the severity of aphasia (Tables 3-6). W was within normal limits for both, $L$ was significantly worse than control participants for backward span. $S$ and $P$ 
Meteyard, L., Bruce, C., Edmundson, A., \& Oakhill, J. (2014). Profiling text

comprehension impairments in aphasia. Aphasiology, (ahead-of-print), 1-28.

were significantly worse than control participants for both forward and backward span.

Meta-Cognitive skills: error detection

W was within normal limits for both versions of the error detection task (Table 3)

$\mathrm{L}$ was significantly worse than control participants in detecting content errors in both versions of the task (easy and hard; Table 4). S was significantly worse than controls in the easy version, but within normal limits for the hard version (Table 5). P was able to complete the easier version within normal limits but unable to finish the task in the hard (longer) version (Table 6), showing a possible effect of passage length on either her performance or confidence. Responses showed that difficulties were in detecting the contradictions, not in misidentifying consistent passages as contradictory ( $\mathrm{L}$ made one false positive error in the easy condition). See Appendix 2 Table 4 for a break down of responses.

Meta-cognitive strategies: self-report on reading strategies.

Three out of four participants scored low to medium for all reading strategies (W, L and $\mathrm{P}$ ) (Table 7). Only $\mathrm{S}$ scored medium to high for using all strategies, showing that she perceived herself to take an active approach to reading.

\section{Table 7: Scores for MARSI reading strategies}

Key: High $=>3.5$, Medium $=2.5-3.4$, Low $=<2.4$

A high score indicates using a strategy often, with a low score indicating that these strategies are used infrequently.

\begin{tabular}{llll}
\hline PT ID & Strategy Score & & \\
\hline & Global & Problem Solving & Support \\
W & 2.9 & 3.3 & 2.7 \\
L & 2.5 & 3 & 2.1 \\
S & 3.5 & 4 & 3.3 \\
P & 1.9 & 2.3 & 2.9 \\
\hline
\end{tabular}


Meteyard, L., Bruce, C., Edmundson, A., \& Oakhill, J. (2014). Profiling text

comprehension impairments in aphasia. Aphasiology, (ahead-of-print), 1-28.

\section{Discussion}

We presented assessment data for a small case-series of individuals with aphasia who reported adequate reading of single words and sentences, but poor reading of text. The profiles of the four participants presented a mixed picture. We will now discuss the different profiles observed in these individuals, and any patterns emerging across cases.

W, the individual who presented with mild/resolved aphasia, was within normal limits across all measures of linguistic processing (single word and sentences) as well as verbal working memory. She was also within normal limits for sentence verification (representing the text base) and error detection (comprehension monitoring). Her performance on inferencing was more ambiguous. She was outside the normal range for both local and global inferences, and for functional and inferential subtests on the MCLA. However, without being able to compare these scores directly to control data it is difficult to make a reliable interpretation. Further work with more sensitive assessments and complete control data is needed. There is evidence that difficulties with inferencing are correlated with aphasia secondary to left-hemisphere lesions, despite this skill typically being associated with right hemisphere lesions (Zaidel, Kasher, Soroker, \& Batori, 2002). For individuals with difficulties in inferencing (as in $\mathrm{TBI}$ ), rehabilitation approaches can teach strategies that specifically target links to background knowledge. For example, summarizing, selfquestioning, clarifying and predicting content (Rich \& Shepherd, 1993) or supporting active manipulation of the text content by using prompts to organize key points (Sohlberg, Griffiths \& Fickas, 2014). It is also worth noting here that as W was bilingual, this may have offered some 'cognitive protection' and made her better able 
Meteyard, L., Bruce, C., Edmundson, A., \& Oakhill, J. (2014). Profiling text comprehension impairments in aphasia. Aphasiology, (ahead-of-print), 1-28. to recover from aphasia and/or manage her impairment more effectively (e.g. for similar accounts in protection against cognitive decline from multilingualism see Perquin et al, 2013). A clearer picture emerged for $L$ (mild aphasia). He showed a residual impairment in word comprehension. He was the only participant who showed poorer performance than controls on sentence verification (representation of the text base), and he also showed the clearest deficits in error detection - detecting only two of a possible 6 content errors in both easy and hard versions of this task. His pattern indicates a residual impairment in lexico-semantic access, likely compounded by a fast reading speed and a mild reduction in working memory. This affects his ability to extract meanings from individual words and make both local and global inferences. This is in line with the finding that successful access to word meaning (i.e. vocabulary knowledge) is important for successful reading comprehension (Beck, Perfetti, \& McKeown, 1982; Guo et al., 2011).

There was no clear mapping between sentence comprehension deficits and text level impairments. It could be that difficulties with syntax will lead to difficulties with text, with syntactic parsing as necessary for both the shallow text-base representation and the richer situation model (Perfetti, 2000). However, the data from S and P indicate otherwise. S (mild aphasia) and $\mathrm{P}$ (moderate aphasia) had slow reading speed, oral reading difficulties, and impairments in sentence comprehension and verbal working memory. Despite their more severe sentence comprehension impairments, both scored within normal limits for sentence verification and had relatively intact error detection. So both individuals had capacity to read at the text level. This parallels findings in spoken comprehension, in which a degree of redundancy in discourse processing appears to compensate for difficulties at the sentence level. For example, Stachowiak et al (1977) found no difference between the performance of individuals with aphasia and an adult control group for the comprehension of short, spoken passages, despite the fact that the individuals with aphasia had marked 
Meteyard, L., Bruce, C., Edmundson, A., \& Oakhill, J. (2014). Profiling text comprehension impairments in aphasia. Aphasiology, (ahead-of-print), 1-28. difficulties with sentence comprehension. Elsewhere, it has been found that sentence comprehension improves when contextual information is provided prior to assessment (Cannito, Vogel, \& Pierce, 1991; Hough, Pierce, \& Cannito, 1989; Nicholas \& Brookshire, 1983). In contrast to this, there is evidence that syntactically complex sentence do affect the ability to comprehend spoken discourse (e.g. when comprehension questions target information presented within a complex syntactic structure; Levy et al, 2012). Together, these findings support the idea that adults with aphasia perform better with discourse because it provides more context. Similarly, text level reading may benefit from a build-up of context over time, as more information is retrieved. However, there is likely to be an effect of syntactic complexity for written comprehension, and assessments that evaluate this systematically will need to be developed (for an assessment tackling this for spoken discourse, see Levy et al, 2012).

Whilst $\mathrm{P}$ was unable to complete the error detection task for longer texts, it was not clear that this due to greater difficulties with sentence comprehension. It may have been due to more severe deficits in working memory resources and her beliefs about her reading capabilities. Both $\mathrm{S}$ and $\mathrm{P}$ had sentence comprehension impairments. However, S was the only individual who reported using different reading strategies frequently. It may be that her use of active reading strategies enabled her to complete the harder monitoring task. Also, S scored within normal limits for functional and inferential reading on the MCLA, better than both $\mathrm{W}$ and $\mathrm{L}$, who did not have sentence comprehension impairments. This finding is extremely encouraging, as it suggests that sentence comprehension deficits are not a barrier to successful text level reading, especially when an appropriate strategy is applied (as it is can be in the MCLA, when texts can be revisited). In the existing literature on treating text comprehension impairments in aphasia, strategy use (e.g. summarizing, taking an active approach to reading) has already been implemented with some success 
Meteyard, L., Bruce, C., Edmundson, A., \& Oakhill, J. (2014). Profiling text comprehension impairments in aphasia. Aphasiology, (ahead-of-print), 1-28.

(Meteyard et al., 2010; Potts \& Morris, 2010).

The findings of this study, in particular L's performance, support the relative importance of word meaning over syntactic parsing for building a representation of the text. When L's performance is examined, it appears to be access to single word meaning that is more critical for building a representation of the text. This is possibly because a lot of information can be extracted from the concatenation of words as they are read (e.g. Breznitz et al, 2013).

Finally, there appeared to be a patterning of verbal working memory with performance on global inferences. Verbal working memory (VWM) is well documented to be impaired in aphasia (Caplan et al., 2013; Caspari, Parkinson, LaPointe, \& Katz, 1998; Mayer \& Murray, 2012). Three of the participants (L, S and P) showed a pattern in which VWM span was reduced and scores on global inferences were worse than for local inferences. Error analysis showed that having the text present did not always mean an answer could be given. There were numerous omission errors for the inferential texts of the MCLA (when texts can be revisited). In addition, errors on the global inferencing task (texts cannot be revisited) often resulted in direct quotes from the text. Therefore, participants were able to retain information about the text base when the text was removed (e.g. to quote from it), but having the text present did not always make answering inferencing questions easier. Cain \& Oakhill (1999) found that when the text was provided to children for them to check, global inferences did not benefit as much as local inferences. This supports the hypothesis that global inferences are more vulnerable to disruption, and perhaps more sensitive to deficits in other component processes, such as working memory. Previous research with healthy adults has shown that those with low working memory capacity may have to trade off keeping the immediate coherence of what they read (the text base) at the expense of an overall situation model (Whitney, 
Meteyard, L., Bruce, C., Edmundson, A., \& Oakhill, J. (2014). Profiling text comprehension impairments in aphasia. Aphasiology, (ahead-of-print), 1-28.

Richie \& Clark, 1991). Two of the three participants in this study with reduced VWM capacity were within normal limits for sentence verification (our assessment of the text-base representation), lending an element of support to this interpretation. However, further research is needed to clarify this relationship. For example, our assessments of inferencing were flawed. In the MCLA, it is possible that different kinds of inference are tested across the passages, as there is no annotation of which questions tap which kinds of inference. Instead, the whole texts are classed as 'functional/factual' or 'inferential'. In the local/global inference task created for this study, controls were at ceiling (preventing significance testing). For both tasks, it is likely that comprehension difficulties made understanding some questions problematic. Responses demanded phrases to be generated, placing those with production difficulties at a disadvantage. However, it appears that inferencing may be an area of difficulty for text comprehension in post-stroke aphasia, as it is in TBI (Ferstl, Guthke \& von Cramon, 2002; Sohlberg, Griffiths \& Fickas; 2014). For rehabilitation, strategies that encourage reflection and the generation of information (e.g. note taking) or explicit retrieval of general knowledge (e.g. comparing against similar situations or events) may be of benefit. In addition, therapeutic work that specifically targets the maintenance of information and sustained attention may also benefit text reading (Coelho, 2005; Sinotte \& Coelho, 2007), although it remains to be seen how this impacts inferencing specifically.

\section{Limitations and future research}

The assessments used here need to be standardized and improved. In particular, complete normative data for measures of severity (Crawford \& Howell, 1998) are needed, that gives sample size, mean and standard deviation values. The materials for the local and global inferencing task should be expanded so controls are not at ceiling. The number of trials on the inferencing and sentence verification tasks should be increased so that data from these tasks is more reliable. Another potential flaw is 
Meteyard, L., Bruce, C., Edmundson, A., \& Oakhill, J. (2014). Profiling text

comprehension impairments in aphasia. Aphasiology, (ahead-of-print), 1-28.

that the sentence verification task is open to interpretation, and we did not provide training for participants. We used an 'old' / 'new' choice (Royer, 1979; Royer, Hastings \& Hook, 1979) where other studies have used a 'true' / 'false' choice in which people judge whether the sentence fits the meaning of the original passage (Sohlberg, Griffiths \& Fickas, 2014). Providing a practice session with feedback, as well as increasing the number of trials, would help to give clearer results. The sentence verification paradigm is particularly useful, since it does not require spoken or written output. It can also be expanded to include inferencing (e.g. Sohlberg, Griffiths \& Fickas, 2014). It would be particularly useful to develop materials testing the text-base (paraphrase), retention of fine-grained word meaning (meaning change items) and inferencing (local and global). This, in combination with measures of working memory and error detection, could provide a potentially sensitive set of measures for understanding text reading difficulties in aphasia. We are currently working towards this aim.

\section{Conclusion}

We completed a small case-series that assessed text comprehension impairments in four individuals with aphasia post-stroke. From the literature on healthy adults and children we identified a set of component processes that give a profile of text comprehension ability. We identified patterns of impairment, which suggest a critical role for some linguistic (access to word meaning) and cognitive skills (verbal working memory). In addition, a pattern was observed for a relationship between verbal working memory and the integration of background knowledge (global inferences). Further research is needed to explore how sentence comprehension ties into text reading. Critically, we recommend assessing verbal working memory and inferencing skills for any individual with aphasia who presents with text reading difficulties. 
Meteyard, L., Bruce, C., Edmundson, A., \& Oakhill, J. (2014). Profiling text comprehension impairments in aphasia. Aphasiology, (ahead-of-print), 1-28.

Assessing the profile of text comprehension is key in understanding impairments at this level, and in targeting rehabilitation.

\section{Acknowledgements}

We would like to thank Alice Albery, Sarah Green, Sophie Clarke and Laurie Clarke for help with data collection and initial analyses. Thanks to Alison Cox for recommending the assessment of working memory and to the reviewers for very useful comments on the first draft. Our sincere thanks goes to the individuals with aphasia who gave their valuable time and feedback during the development and testing of the assessment tasks.

\section{References}

Barbey, A. K., Colom, R., \& Grafman, J. (2014). Neural mechanisms of discourse comprehension: a human lesion study. Brain, 137(1), 277-287.

Beck, I. L., Perfetti, C., \& McKeown, M. G. (1982). Effects of long-term vocabulary instruction on lexical access and reading comprehension. Journal of Educational Psychology, 74(4), 506-521.

Breznitz, Z., Shaul, S., Horowitz-Kraus, T., Sela, I. N., M., \& Karni, A. (2013). Enhanced reading by training with imposed time constraint in typical and dyslexic adults. Nature communications, 4(1486).

Cain, K., \& Oakhill, J. (1999). Inference making ability and its relation to comprehension failure in young children. Reading and Writing, 11(5-6), 489503.

Cain, K., \& Oakhill, J. (2011). Matthew Effects in Young Readers Reading Comprehension and Reading Experience Aid Vocabulary Development. Journal of learning disabilities, 44(5), 431-443.

Cain, K., Oakhill, J., Barnes, M.A. \& Bryant, P.E. (2001) Comprehension skill, inference-making ability, and their relation to knowledge. Memory \& Cognition, 29(6), pp. 850-859.

Cain, K., Oakhill, J., \& Bryant, P. (2004). Children's Reading Comprehension Ability: Concurrent Prediction by Working Memory, Verbal Ability, and Component Skills. Journal of Educational Psychology, 96(1), 31-42.

Cannito, M. P., Vogel, D., \& Pierce, R. S. (1991). Contextualised sentence comprehenion in nonfluent aphasia: Predictiveness and severity of comprehension impairment. Clinical Aphasiology, 20(111-120).

Caplan, D. N., Michaud, J., \& Hufford, R. (2013). Short-term memory, working memory and syntactic comprehension in aphasia. Cognitive Neuropsychology, 30(2), 77-109.

Carretti, B., Borella, E., Cornoldi, C., \& De Beni, R. (2009). Role of working memory in explaining the performance of individuals with specific reading comprehension difficulties: A meta-analysis. Learning and Individual Differences, 19, 246-251. 
Meteyard, L., Bruce, C., Edmundson, A., \& Oakhill, J. (2014). Profiling text comprehension impairments in aphasia. Aphasiology, (ahead-of-print), 1-28.

Caspari, I., Parkinson, S. R., LaPointe, L., \& Katz, R. C. (1998). Working Memory and Aphasia. Brain and Cognition, 37(2), 205-223.

Cherney, L. R. (2004). Aphasia, Alexia, and Oral Reading. Topics in Stroke Rehabilitation, 11(1), 22-36.

Cocks, N., Pritchard, M., Cornish, H., Johnson, N., \& Cruice, M. (2013). A "novel" reading therapy programme for reading difficulties after a subarachnoid haemorrhage. Aphasiology, 27(5), 509-531.

Coelho, C. (2005). Direct attention as a treatment for reading impairment in mild aphasia. Aphasiology, 19(3), 275-283.

Crawford, J. R., \& Garthwaite, P. H. (2002). Investigation of the single case in neuropsychology: Confidence limits on the abnormality of test scores and test score differences. Neuropsychologia, 40, 1196-1208.

Crawford, J. R., Garthwaite, P. H., \& Porter, S. (2010). Point and interval estimates of effect sizes for the case-controls design in neuropsychology: Rationale, methods, implementations, and proposed reporting standards. Cognitive Neuropsychology, 27, 245-260.

Crawford, J. R., \& Howell, D. C. (1998). Comparing an individual's test score against norms derived from small samples. The Clinical Neuropsychologist, 12, 482486.

Crisp, J., \& Lambon Ralph, M. A. (2006). Unlocking the nature of the phonologicaldeep dyslexia continuum: The keys to reading aloud are in phonology and semantics. Journal of Cognitive Neuroscience, 18(3), 348-362.

Ellmo, W., Graser, J., Krchnavek, B., Hauck, K., \& Calabrese, D. (1995). Measure of Cognitive-Linguistic Abilities (MCLA): Florida: The Speech Bin Inc.

Erhlich, M., Redmond, M., \& Tardieu, H. (1999). Processing of anaphoric devides in young skilled and less skilled comprehenders: Differences in metacognitive monitoring. Reading and Writing, 11(29-63).

Ferstl, E. C., Guthke, T., \& von Cramon, D. Y. (2002). Text comprehension after brain injury: Left prefrontal lesions affect inference processes. Neuropsychology, 16(3), 292.

Ferstl, E. C., Neumann, J., Bogler, C., \& Von Cramon, D. Y. (2008). The extended language network: a meta analysis of neuroimaging studies on text comprehension. Human brain mapping, 29(5), 581-593.

Fincher-Kiefer, R. (2001). Perceptual components of situation models. Memory \& Cognition, 29(2), 336-343.

Funnell, E. (Ed.). (2000). Case Studies in the Neuropsychology of Reading: Hove, UK: Psychology Press, Taylor Francis.

Graesser, A. C., Singer, M., \& Trabasso, T. (1994). Constructing inferences during narrative text comprehension. Psychological Review, 101(3), 371-395.

Guo, Y., Roehrig, A. D., \& Williams, R. S. (2011). The Relation of Morphological Awareness and Syntactic Awareness to Adults' Reading Comprehension: Is Vocabulary Knowledge a Mediating Variable? Journal of Literacy Research, 43(2), 159-183.

Hannon, B. (2012). Understanding the Relative Contributions of Lower-Level Word Processes, Higher-Level Processes, and Working Memory to Reading Comprehension Performance in Proficient Adult Readers. Reading Research Quarterly, 47(2), 125-152.

Hough, M. S., Pierce, R. S., \& Cannito, M. P. (1989). Contextual influences in aphasia: Effects of predictive versus nonpredictive narratives. Brain and Language, 36(2), 325-334.

Jensen, L. R. (2000). Canonical structure without access to verbs?. Aphasiology, 14(8), 827-850.

Kay, J., Lesser, R., \& Coltheart, M. (1992) Psycholinguistic assessments of language processing in aphasia. LEA, Hove. 
Meteyard, L., Bruce, C., Edmundson, A., \& Oakhill, J. (2014). Profiling text comprehension impairments in aphasia. Aphasiology, (ahead-of-print), 1-28.

Kertesz, A. (1982). Western Aphasia Battery. Orlando, FL, USA.: Grune \& Stratton Inc.

Kim, M., \& Russo, S. (2010). Multiple Oral Rereading (MOR) Treatment: Who Is It For? . Contemporary Issues in Communication Science and Disorders, 37, 58-68.

Kletzien, S. B. (1991). Strategy Use by Good and Poor Comprehenders Reading Expository Text of Differing Levels. Reading Research Quarterly, 26, 67-86.

Landi, N. (2010). An examination of the relationship between reading comprehension, higher-level and lower-level reading sub-skills in adults. Reading and Writing, 23(6), 701-717. doi: 10.1007/s11145-009-9180-z

LaPointe, L., \& Horner, J. (1998). Reading Comprehension Battery for Aphasia: Second Edition: Texas: Pro-Ed.

Lee Swanson, H., Howard, C. B., \& Saez, L. (2006). Do Different Components of Working Memory Underlie Different Subgroups of Reading Disabilities? Journal of learning disabilities, 39, 252-269.

Leff, A. P., Spitsyna, G., Plant, G. T., \& Wise, R. J. S. (2006). Structural anatomy of pure and hemianopic alexia. Journal of Neurology, Neurosurgery \& Psychiatry, 77(9), 1004-1007.

Levy, J., Hoover, E., Waters, G., Kiran, S., Caplan, D., Berardino, A., \& Sandberg, C. (2012). Effects of Syntactic Complexity, Semantic Reversibility, and Explicitness on Discourse Comprehension in Persons With Aphasia and in Healthy Controls. American Journal of Speech-Language Pathology, 21(2), S154-S165.

Long, D., \& Chong, J. L. (2001). Comprehension skill and global coherence: A paradoxical picture of poor comprehenders' abilities. Journal of Experimental Psychology: Learning, Memory and Cognition, 27(6), 1424.

Lynch, K. E., Damico, J. S., Abendroth, K. J., \& Nelson, R. L. (2013). Reading performance subsequent to aphasia: Strategies applied during authentic reading. Aphasiology, 27(6), 723-739.

Lynch, K. E., Damico, J. S., Damico, H. L., Tetnowski, J., \& Tetnowski, J. (2009). Reading skills in an individual with aphasia: The usefulness of meaningbased clinical applications. Asia Pacific Journal of Speech, Language and Hearing, 12(3), 221-234.

Mayer, J. F., \& Murray, L. L. (2012). Measuring working memory deficits in aphasia. Journal of Communication Disorders, 45(5), 325-339.

McBride Chang, C. (2004). Reading Comprehension Children's literacy development. London: Arnold.

McVay, J. C., \& Kane, M. J. (2012). Why does working memory capacity predict variation in reading comprehension? On the influence of mind wandering and executive attention. Journal of experimental psychology: general, 141(2), 302.

Meteyard, L., Bruce, C., Edmundson, A., \& Ayre, J. (2010). Intervention for higher level reading difficulties: a case study. Paper presented at the British Aphasiology Society Therapy Symposium, Newcastle.

Mokhtari, K., \& Reichard, C. (2002). Assessing students' metacognitive awareness of reading strategies. Journal of Educational Psychology, 94(2), 249-259.

Nicholas, L. E., \& Brookshire, R. H. (1983). Syntactic simplification and context: Effects on sentence comprehension by aphasic adults. Paper presented at the 13th Clinical Aphasiology Conference, Phoenix, AZ

Oakhill, J., Hartt, J., \& Samols, D. (2005). Levels of comprehension monitoring and working memory in good and poor comprehenders. Reading and Writing, 18, 657-686.

Penn, C., \& Jones, D. (2000). Functional communication and the workplace: A neglected domain. In L. E. Worral \& C. M. Frattali (Eds.), Neurogenic Communication Disorders: A Functional Approach (pp. 103-124). New York: Thieme Publishers. 
Meteyard, L., Bruce, C., Edmundson, A., \& Oakhill, J. (2014). Profiling text comprehension impairments in aphasia. Aphasiology, (ahead-of-print), 1-28.

Perfetti, C.A. (2000) Comprehending written language: a blueprint of the reader. In C.M. Brown \& P. Hagoort (Eds) The Neurocognition of Language (Ch.6, pp 167-208), Oxford Press, UK.

Perquin, M., Vaillant, M., Schuller, A. M., Pastore, J., Dartigues, J. F., Lair, M. L., Diederich, N. \& MemoVie Group. (2013). Lifelong exposure to multilingualism: new evidence to support cognitive reserve hypothesis. PloS one, 8(4), e62030.

Potts, A., \& Morris, J. (2010). Reading for Meaning: Attentive Reading and Constrained Summarisation (ARCS) as a therapy approachAmy (poster). Paper presented at the British Aphasiology Society Therapy Symposium, Newcastle University.

Rich, R., \& Shepherd, M. J. (1993). Teaching text comprehension strategies to adult poor readers. Reading and Writing, 5(4), 387-402.

Rinck, M., \& Bower, G. H. (2000). Temporal and spatial distance in situation models. Memory \& Cognition, 28(8), 1310-1320.

Rinck, M., Hahnel, A., Bower, G. H., \& Glowalla, U. (1997). The metrics of spatial situation models. Journal of Experimental Psychology: Learning, Memory and Cognition, 23, 622-637.

Rogalsky, Y., \& Edmonds, L. A. (2008). Attentive Reading and Constrained Summarisation (ARCS) treatment in primary progressive aphasia: A case study. Aphasiology, 22(7-8), 763-775.

Royer, J. (1979). A sentence verification technique for measuring reading comprehension: Amsterdam: University of Massachusetts.

Royer, J. M., Hastings, C. N., \& Hook, C. (1979). A sentence verification technique for measuring reading comprehension. Journal of Literacy Research, 11(4), 355-363.

Schreiber, F. J. (2005). Metacognition and Self-Regulation in Literacy. In S. E. Israel, C. C. Block, K. L. Bauserman \& K. Kinnucan-Welsch (Eds.), Metacognition in Literacy Learning: Theory, Assessment, Instruction, and Professional Development. New Jersey: Taylor \& Francis.

Sinotte, M. P., \& Coelho, C. A. (2007). Attention training for reading impairment in mild aphasia: A follow-up study. NeuroRehabilitation, 22(4), 303-310.

Slottje, D. J. (1991). Measuring the Quality of Life Across Countries. The Review of Economics and Statistics, 73(4), 684-693.

Snow, C. (2002). Reading for understanding: Toward a research and development program in reading comprehension Retrieved from http://www.rand.org/pubs/monograph reports/MR1465/

Sohlberg, M. M., Griffiths, G. G., \& Fickas, S. (2014). An Evaluation of Reading Comprehension of Expository Text in Adults With Traumatic Brain Injury. American Journal of Speech-Language Pathology, 23(2), 160-175.

Stachowiak, F.-J., Huber, W., Poeck, K., \& Kerschensteiner, M. (1977). Text comprehensino in aphasia. Brain and Language, 4(2), 177-195.

van Dijk, T. A., \& Kintsch, W. (Eds.). (1983). Strategies of Discourse Comprehension. New York/London: Academic Press.

Webb, W., \& Love, R. (1983). Reading problems in chronic aphasia. Journal of Speech and Hearing Disorders, 4, 164-171.

Webster, J., Morris, J., Connor, C., Horner, R., McCormac, C., \& Potts, A. (2013). Text level reading comprehension in aphasia: What do we know about therapy and what do we need to know?. Aphasiology, 27(11), 1362-1380.

Whitney, P., Ritchie, B. G., \& Clark, M. B. (1991). Working memory capacity and the use of elaborative inferences in text comprehension. Discourse Processes, 14(2), 133-145.

Wimmer, H., Mayringer, H., \& Landerl, K. (1998). Poor Reading: A Deficit in SkillAutomatization or a Phonological Deficit? Scientific Studies of Reading, 2(4), 321-340. 
Meteyard, L., Bruce, C., Edmundson, A., \& Oakhill, J. (2014). Profiling text comprehension impairments in aphasia. Aphasiology, (ahead-of-print), 1-28.

Zaidel, E., Kasher, A., Soroker, N., \& Batori, G. (2002). Effects of right and left hemisphere damage on performance of the "Right Hemisphere Communication Battery". Brain and language, 80(3), 510-535.

Zwaan, R. (1999). Situation Models: The Mental Leap Into Imagined Worlds. Current Directions in Psychological Science, 8(1), 15-18.

Zwaan, R., \& Ross, B.H. (2004). The immersed experiencer: toward an embodied theory of language comprehension. The Psychology of Learning and Motivation (Vol. 44, pp. 35). San Diego, CA.: Academic Press.

Zwaan, R., \& Radvansky, G. A. (1998). Situation models in language comprehension and memory. Psychological Bulletin, 123, 162-185.

\section{Key for Tables 3-6}

*one-tailed probability. Grey shading indicates the participant's score is significantly

below control data (Sig test) or below and outside the normal range (participant's

score, e.g. 'W's score'). Spoken words = spoken word to picture matching (PALPA

47), Written words = written word to picture matching (PALPA 48), Spoken sentences

$=$ spoken sentence to picture matching (PALPA 55), Written sentences $=$ written

sentence to picture matching (PALPA 56), VWM = verbal working memory. 
Meteyard, L., Bruce, C., Edmundson, A., \& Oakhill, J. (2014). Profiling text comprehension impairments in aphasia. Aphasiology, (aheadof-print), 1-28.

Table 3: Patient W performance on assessment tasks.

\begin{tabular}{|c|c|c|c|c|c|c|c|c|c|c|}
\hline \multirow[t]{2}{*}{ Task } & \multicolumn{3}{|c|}{ Control sample } & \multirow[t]{2}{*}{$\begin{array}{l}\text { W's } \\
\text { score* }\end{array}$} & \multicolumn{2}{|c|}{ Sig. test* } & \multicolumn{2}{|c|}{$\begin{array}{l}\text { Est \% of controls } \\
\text { obtaining lower } \\
\text { score than W } \\
\end{array}$} & \multicolumn{2}{|c|}{$\begin{array}{l}\text { Estimated effect size (z- } \\
\text { cc) for difference between } \\
\mathrm{W} \text { and controls }\end{array}$} \\
\hline & $\mathrm{n}$ & Mean & SD & & $\mathrm{t}$ & $\mathrm{p}$ & Point & $(95 \% \mathrm{CI})$ & Point & (95\% CI) \\
\hline Spoken words & 31 & 39.3 & 1.1 & 39 & -0.27 & 0.4 & 39.6 & 26.5 to 53.6 & -0.27 & -0.627 to 0.090 \\
\hline Written words & 32 & 39.5 & 1.0 & 39 & -0.46 & 0.3 & 32.5 & 20.4 to 46.1 & -0.46 & -0.827 to 0.097 \\
\hline Synonym judgment & 8 & 59.1 & 1.3 & 60 & 0.66 & 0.3 & 73.5 & 46.1 to 92.8 & 0.70 & -0.098 to 1.464 \\
\hline Spoken Sentences & 26 & & & & & & & & & \\
\hline Reversible & & 19.4 & 0.9 & 19 & -0.48 & 0.32 & 31.80 & 18.64 to 46.94 & -0.49 & -0.89 to -0.08 \\
\hline Non-reversible & & 15.6 & 0.8 & 16 & 0.48 & 0.32 & 68.17 & 53.03 to 81.34 & 0.49 & 0.08 to 0.89 \\
\hline Gap as subject & & 7.7 & 0.7 & 8 & 0.36 & 0.36 & 63.88 & 48.62 to 77.64 & 0.37 & -0.04 to 0.76 \\
\hline Gap not as subject & & 7.2 & 0.7 & 7 & -0.31 & 0.38 & 38.02 & 24.03 to 53.30 & -0.31 & -0.71 to 0.08 \\
\hline Converse relations & & 7.0 & 0.9 & 7 & 0.00 & 0.50 & 50.0 & 35.03 to 64.97 & 0.00 & -0.38 to 0.38 \\
\hline Written Sentences & 27 & & & & & & & & & \\
\hline Reversible & & 19.2 & 1.1 & 19 & -0.13 & 0.45 & 44.73 & 30.36 to 59.63 & -0.14 & -0.52 to 0.24 \\
\hline Non-reversible & & 15.5 & 0.8 & 15 & -0.64 & 0.27 & 26.76 & 14.69 to 41.30 & -0.64 & -1.05 to -0.22 \\
\hline Gap as subject & & 7.6 & 0.6 & 8 & 0.61 & 0.27 & 72.57 & 57.98 to 84.77 & 0.62 & 0.20 to 1.03 \\
\hline Gap not as subject & & 7.7 & 0.7 & 7 & -1.15 & 0.13 & 12.96 & 4.84 to 24.99 & -1.17 & -1.66 to -0.68 \\
\hline Converse relations & & 6.9 & 1.1 & 8 & 1.07 & 0.15 & 85.17 & 72.59 to 94.02 & 1.09 & 0.60 to 1.56 \\
\hline VWM forward score & 8 & 10.3 & 1.7 & 9 & 0.71 & 0.3 & 25.1 & 6.4 to 52.5 & -0.74 & -1.521 to 0.064 \\
\hline VWM backward score & 8 & 8 & 2.5 & 5 & -1.15 & 0.2 & 14.3 & 1.6 to 39.5 & -1.23 & -2.137 to -0.266 \\
\hline Inferencing - local & 7 & 10 & 0 & 8.5 & & & & & & \\
\hline Inferencing - global & 7 & 10 & 0 & 8 & & & & & & \\
\hline Error detection - easy & 5 & 5.6 & 0.6 & 5 & -0.99 & 0.2 & 18.7 & 1.39 to 53.3 & -1.10 & -2.201 to 0.082 \\
\hline Error detection - hard & 8 & 5.3 & 1.2 & 6 & 0.61 & 0.3 & 71.8 & 44.3 to 91.8 & 0.64 & -0.142 to 1.393 \\
\hline Sentence verification & 7 & 11.6 & 2.1 & 10 & -0.71 & 0.3 & 25.2 & 5.6 to 54.6 & -0.76 & -1.587 to 0.116 \\
\hline Reading speed & 5 & 299.4 & 125.7 & 99 & -1.46 & 0.1 & 10.9 & 0.16 to 42.67 & -1.59 & -2.94 to -0.19 \\
\hline
\end{tabular}


Meteyard, L., Bruce, C., Edmundson, A., \& Oakhill, J. (2014). Profiling text comprehension impairments in aphasia. Aphasiology, (aheadof-print), 1-28.

Table 4: Patient L performance on assessment tasks.

\begin{tabular}{|c|c|c|c|c|c|c|c|c|c|c|}
\hline \multirow[t]{2}{*}{ Task } & \multicolumn{3}{|c|}{ Control sample } & \multirow[t]{2}{*}{$\begin{array}{l}\text { L's } \\
\text { score* }\end{array}$} & \multicolumn{2}{|c|}{ Sig. test* } & \multicolumn{2}{|c|}{$\begin{array}{l}\text { Est \% of controls } \\
\text { obtaining lower score } \\
\text { than L }\end{array}$} & \multicolumn{2}{|c|}{$\begin{array}{l}\text { Estimated effect size (z-cc) } \\
\text { for difference between } L \\
\text { and controls }\end{array}$} \\
\hline & $\mathrm{n}$ & Mean & SD & & $\mathrm{t}$ & $\mathrm{p}$ & Point & $(95 \% \mathrm{CI})$ & Point & $(95 \% \mathrm{CI})$ \\
\hline Written words & 32 & 39.47 & 1.01 & 38 & -1.43 & 0.08 & 8.09 & 2.5 to 17.11 & -1.4 & -1.95 to -0.95 \\
\hline Synonym judgment & 8 & 59.13 & 1.25 & 50 & -6.9 & 0.0 & 0.01 & 0.0 to 0.02 & -7.3 & -11.13 to -3.52 \\
\hline Spoken Sentences & 26 & & & & & & & & & \\
\hline Gap as subject & & 7.7 & 0.7 & 7 & -1.02 & 0.16 & 15.81 & 6.48 to 28.92 & -1.04 & -1.52 to -0.56 \\
\hline Gap not as subject & & 7.2 & 0.7 & 7 & -0.31 & 0.38 & 38.02 & 24.03 to 53.30 & -0.31 & -0.71 to 0.08 \\
\hline Converse relations & & 7.0 & 0.9 & 4 & -3.13 & 0.00 & 0.22 & 0.00 to 1.30 & -3.19 & -4.14 to -2.23 \\
\hline Written Sentences & 27 & & & & & & & & & \\
\hline Reversible & & 19.2 & 1.1 & 20 & 0.76 & 0.23 & 77.26 & 63.15 to 88.46 & 0.77 & 0.34 to 1.20 \\
\hline Non-reversible & & 15.5 & 0.8 & 16 & 0.68 & 0.25 & 74.90 & 60.52 to 86.63 & 0.69 & 0.27 to 1.11 \\
\hline VWM backward score & 8 & 8 & 2.45 & 2 & -2.3 & 0.02 & 2.71 & 0.0 to 15.8 & -2.4 & -3.8 to -1.0 \\
\hline Inferencing - local & 7 & 10 & 0 & 9.5 & & & & & & \\
\hline Inferencing - global & 7 & 10 & 0 & 6.5 & & & & & & \\
\hline Error detection - easy & 5 & 5.6 & 0.55 & 2 & -5.9 & 0.0 & 0.19 & 0.0 to 1.47 & -6.57 & -11.0 to -2.18 \\
\hline Error detection - hard & 8 & 5.25 & 1.17 & 2 & -2.6 & 0.01 & 1.70 & 0.0 to 11.73 & -2.79 & -4.36 to -1.19 \\
\hline Sentence verification & 7 & 11.6 & 2.1 & 7 & -2.1 & 0.04 & 4.22 & 0.0 to 22.2 & -2.21 & -3.61 to -0.76 \\
\hline Reading speed & 5 & 299.4 & 125.7 & 410 & 0.8 & 0.2 & 76.65 & 41.67 to 97.13 & 0.88 & -0.21 to 1.90 \\
\hline
\end{tabular}


Meteyard, L., Bruce, C., Edmundson, A., \& Oakhill, J. (2014). Profiling text comprehension impairments in aphasia. Aphasiology, (aheadof-print), 1-28.

Table 5: Patient S performance on assessment tasks

\begin{tabular}{|c|c|c|c|c|c|c|c|c|c|c|}
\hline \multirow[t]{2}{*}{ Task } & \multicolumn{3}{|c|}{ Control sample } & \multirow[t]{2}{*}{$\begin{array}{l}\text { S's } \\
\text { score* }\end{array}$} & \multicolumn{2}{|c|}{ Sig. test* } & \multicolumn{2}{|c|}{$\begin{array}{l}\text { Est \% of controls } \\
\text { obtaining lower } \\
\text { score than } S\end{array}$} & \multicolumn{2}{|c|}{$\begin{array}{l}\text { Estimated effect size (z-cc) } \\
\text { for difference between } S \text { and } \\
\text { controls }\end{array}$} \\
\hline & $\mathrm{n}$ & Mean & SD & & $\mathrm{t}$ & $\mathrm{p}$ & Point & $(95 \% \mathrm{CI})$ & Point & $(95 \% \mathrm{CI})$ \\
\hline Written words & 32 & 39.47 & 1.01 & 39 & -0.27 & 0.4 & 39.6 & 26.52 to 53.6 & -0.27 & -0.627 to 0.090 \\
\hline Synonym judgment & 8 & 59.13 & 1.25 & 57 & -1.6 & 0.07 & 7.6 & 0.25 to 28.5 & -1.71 & -2.8 to -0.57 \\
\hline Spoken Sentences & 26 & & & & & & & & & \\
\hline Gap as subject & & 7.7 & 0.7 & 6 & -241 & 0.01 & 1.19 & 0.06 to 4.77 & -2.45 & -3.22 to -1.67 \\
\hline Gap not as subject & & 7.2 & 0.7 & 6 & -1.71 & 0.05 & 4.98 & 0.94 to 13.12 & -1.74 & -2.35 to -1.21 \\
\hline Converse relations & & 7.0 & 0.9 & 5 & -2.09 & 0.02 & 2.36 & 0.24 to 7.78 & -2.13 & -2.82 to -1.42 \\
\hline Written Sentences & 27 & & & & & & & & & \\
\hline Reversible & & 19.2 & 1.1 & 13 & -5.50 & 0.00 & 0.00 & 0.00 to 0.00 & -5.59 & -7.14 to -4.03 \\
\hline Non-reversible & & 15.5 & 0.8 & 15 & -0.63 & 0.27 & 26.76 & 14.69 to 41.30 & -0.64 & -1.05 to -0.22 \\
\hline VWM backward score & 8 & 8 & 2.45 & 2 & -2.3 & 0.02 & 2.71 & 0.0 to 15.8 & -2.4 & -3.8 to -1.0 \\
\hline Inferencing - local & 7 & 10 & 0 & 9 & & & & & & \\
\hline Inferencing - global & 7 & 10 & 0 & 3.5 & & & & & & \\
\hline Error detection - easy & 5 & 5.6 & 0.55 & 4 & -2.6 & 0.02 & 2.8 & 0.0 to 21.6 & -2.9 & -5.3 to -0.78 \\
\hline Error detection - hard & 8 & 5.25 & 1.17 & 5 & -2.0 & -0.2 & 42.2 & 18.1 to 68.9 & -0.21 & -0.9 to 0.494 \\
\hline Sentence verification & 7 & 11.6 & 2.1 & 9 & -1.16 & 0.14 & 14.48 & 1.30 to 41.82 & -1.24 & -2.22 to -0.21 \\
\hline Reading speed & 5 & 299.4 & 125.7 & 92 & -1.5 & 0.1 & 10.3 & 0.12 to 41.6 & -1.6 & -3.1 to -0.21 \\
\hline
\end{tabular}


Meteyard, L., Bruce, C., Edmundson, A., \& Oakhill, J. (2014). Profiling text comprehension impairments in aphasia. Aphasiology, (aheadof-print), 1-28.

Table 6: Patient $\mathrm{P}$ performance on assessment tasks

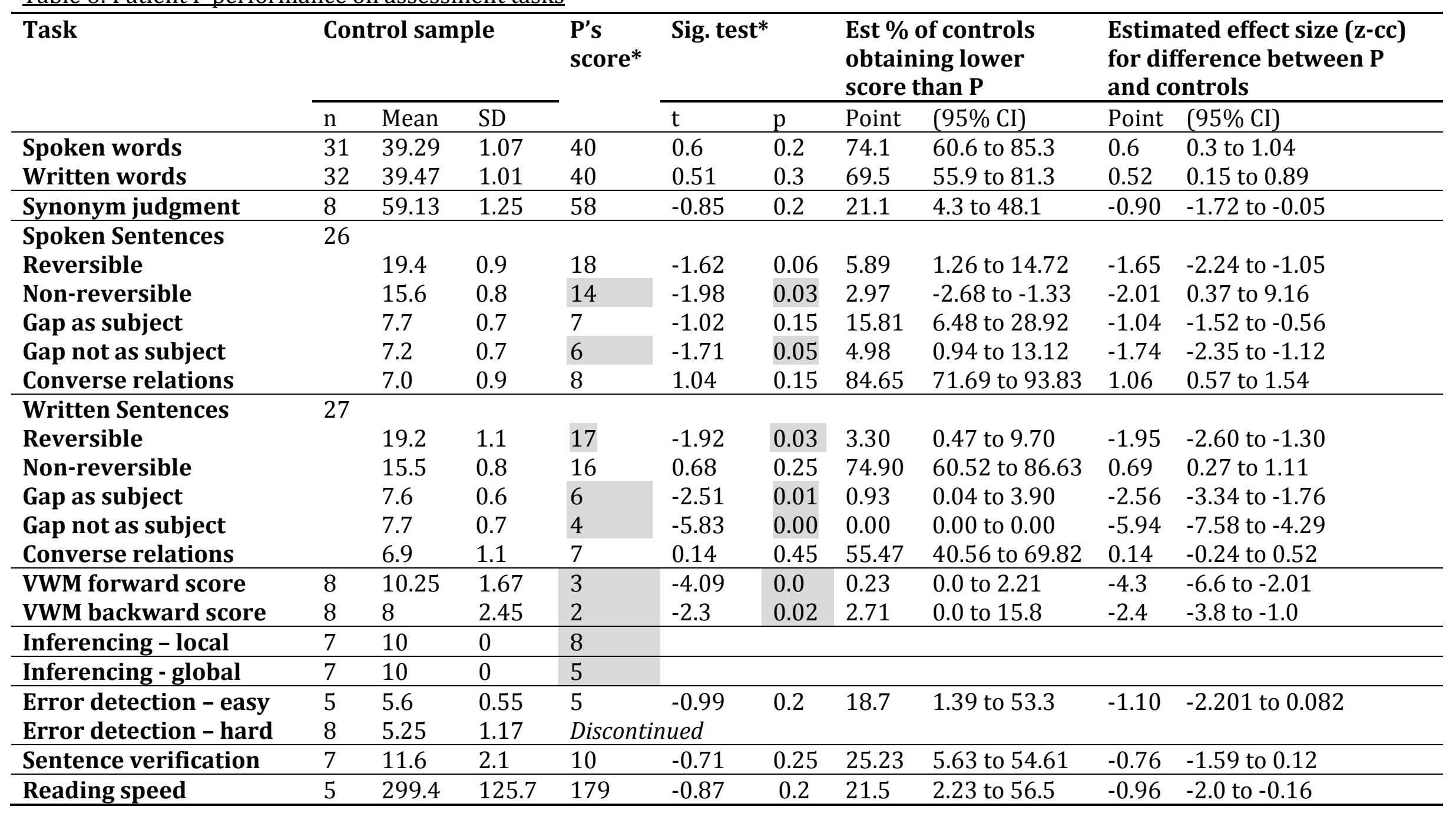


Meteyard, L., Bruce, C., Edmundson, A., \& Oakhill, J. (2014). Profiling text

comprehension impairments in aphasia. Aphasiology, (ahead-of-print), 1-28.

\section{Appendix 1 A}

Example materials from Inferencing task (local and global coherence)

\section{Passage:}

Jenny was late getting home from school on Friday and she was soaking wet when she walked through the door. She was angry because the bus had broken down.

Mum was just in the middle of a job when Jenny walked in. "Take off those wet clothes" mum said. "I was just sorting out the blue items to do first, I can put your jumper in with them now. It will be ready to wear again by Monday". Jenny went upstairs to dry and change out of her wet clothes. But she left a puddle of water in the kitchen by the fridge where she had been standing. Mum looked for the cleaning equipment. She found the bucket in the cupboard under the stairs

\section{Questions:}

1. Why was Jenny angry? (local)

__The bus had broken down

2. Why was Jenny wet? (global)

___t was raining

3. What was Jenny's mum doing? (global)

__Washing clothes

4. Where was the puddle of water? (local) In the kitchen (by the fridge) 
Meteyard, L., Bruce, C., Edmundson, A., \& Oakhill, J. (2014). Profiling text

comprehension impairments in aphasia. Aphasiology, (ahead-of-print), 1-28.

\section{Appendix 1 B}

Error analysis

For the MCLA and local/global inferencing task responses are given as phrases or sentences. For that reason, errors were thematically classified. As errors were analysed, categories were developed to fit patterns within and across patients. The following categories were established after a first pass, with a second pass then made to reclassify errors into those categories.

All examples below are taken verbatim from responses given by participants

\begin{tabular}{|c|c|}
\hline Error type & Example (correct response) \\
\hline \multicolumn{2}{|l|}{$\begin{array}{l}\text { Omission: no response provided or } \\
\text { question passed. }\end{array}$} \\
\hline $\begin{array}{l}\text { Partial: part of the correct answer } \\
\text { (half marks awarded) }\end{array}$ & $\begin{array}{l}\text { Q: If Clean-All gets on your skin, what } \\
\text { two things do you need to do? } \\
\text { A: call the doctor } \\
\text { (call the doctor and wash with water) }\end{array}$ \\
\hline $\begin{array}{l}\text { Missed: wrong information from the } \\
\text { text was given, indicating that the } \\
\text { correct information had been missed }\end{array}$ & $\begin{array}{l}\text { Q: Can meat eaters enjoy this } \\
\text { restaurant? } \\
\text { A: No, because it's all vegetarian } \\
\text { (Yes, the menu is varied / "even the most } \\
\text { diehard meat eaters will find dishes to } \\
\text { tantalize their taste buds") }\end{array}$ \\
\hline $\begin{array}{l}\text { Wrong: wrong information not clearly } \\
\text { taken from the text }\end{array}$ & $\begin{array}{l}\text { Q: What is the toxin of the Great } \\
\text { American Pufferfish and what is it's } \\
\text { antidote? } \\
\text { A: The GAP does not need to puff up so } \\
\text { much } \\
\text { (toxin is broken promises, antidote is } \\
\text { knowledge) }\end{array}$ \\
\hline Quote: answer quoted from the text & $\begin{array}{l}\text { Q: Why did the doctor treat him? } \\
\text { A: The doctor treated.. after a } 12 \\
\text { minute ordeal } \\
\text { (he had been injured/gored by a bull) }\end{array}$ \\
\hline $\begin{array}{l}\text { Other: general or vague answer that } \\
\text { does not address the question, the } \\
\text { question has been misread, or the } \\
\text { participant asked for / required } \\
\text { prompting to get the correct answer }\end{array}$ & $\begin{array}{l}\text { Q: How does the author feel about } \\
\text { meat? } \\
\text { A: I imagine she is opposed to it. } \\
\text { (That it's not necessary for a good meal) } \\
\text { Q: Where is the story about a } \\
\text { discovery? } \\
\text { A: small town } \\
\text { (on page 5) }\end{array}$ \\
\hline
\end{tabular}


Meteyard, L., Bruce, C., Edmundson, A., \& Oakhill, J. (2014). Profiling text

comprehension impairments in aphasia. Aphasiology, (ahead-of-print), 1-28.

\section{Appendix $1 \mathrm{C}$}

Example materials from the sentence verification task

\section{Passage:}

One wonderful thing about grandparents, Tim decided, was the stories they could tell about his parents when they had been young. His favourite story about his mother was the famous pillow caper.

"Nowadays," Grandma said, "a feather pillow is something of a rarity or a luxury. Most people seem content with polyester fillings and such. When your mother was small, we had nothing but feather stuffed in our house. You don't know what comfort is until you've sunk your head into 3,000 bits of goose down."

Sentences: each sentence appeared with 'old' and 'new' underneath, and participants had to mark their choice.

\section{Original}

Most people seem content with polyester fillings and such.

\section{Paraphrase}

Being able to hear stories of when his mum and dad were kids was one of the great things about having grandparents around, Tim concluded.

\section{Meaning change}

His favourite story about his father was the famous pillow caper.

\section{Distracter}

It is always fun visiting grandparents because they take you someplace exciting, like the zoo or the circus. 
Meteyard, L., Bruce, C., Edmundson, A., \& Oakhill, J. (2014). Profiling text

comprehension impairments in aphasia. Aphasiology, (ahead-of-print), 1-28.

\section{Appendix 1 D}

Example materials from error detection.

Inconsistent elements have been are underlined.

\section{Error Detection Easy}

Gorillas

- Gorillas are the largest ape in West Africa.

The male is usually about 2 metres high and they move around by 'knucklewalking'.

They are almost entirely vegetarian; they inhabit the forests of West Africa and search for food in family parties.

. Gorillas usually won't attack unless it's in self defence.

. Gorillas make strong nests in trees for overnight use.

. Gorillas walk around on two legs like humans because their DNA is $98-99 \%$ identical to that of humans.

\section{Error Detection Hard}

Wolf hunting

In the middle ages, wolf hunting was a popular activity that people looked forward to, with almost as much anticipation as the village dances. The hunt often lasted for many hours because the wolves did not want to be captured, so there was usually a long tiring chase, across fields and through woods. The capture of the animal was seen as a great achievement. On their return, the hunters showed off the body of the beast in the village square for all to see. Because the hunt itself was quite brief there was always plenty of time for fun and games afterwards. 
Meteyard, L., Bruce, C., Edmundson, A., \& Oakhill, J. (2014). Profiling text comprehension impairments in aphasia. Aphasiology, (aheadof-print), 1-28.

Appendix 2 Table 1: Errors on background reading assessments

Subtests in which errors were made are given for the RCBA, with more information provided when errors were localized to particular subtests (e.g. oral reading for S and P). For the MCLA, errors were categorized thematically (see Appendix 1B). Correct answers receive 2 points, partial errors received half marks ( 1 point), other errors were marked 0 . Grey shading indicates a score below the normal range (see Table 2).

\begin{tabular}{|c|c|c|c|c|c|}
\hline \multirow[t]{2}{*}{ PT ID } & \multicolumn{2}{|c|}{$\begin{array}{l}\text { Reading Comprehension Battery for Aphasia } \\
\text { (RCBA) }\end{array}$} & \multicolumn{3}{|c|}{$\begin{array}{l}\text { Measure of cognitive linguistic abilities (MCLA) - reading } \\
\text { subtests }\end{array}$} \\
\hline & Core & Supplemental & Functional & Factual & Inferences \\
\hline $\mathbf{W}$ & $\begin{array}{l}\text { Functional Reading } \\
\text { Paragraph Picture } \\
\text { Paragraph Inferential } \\
\text { Morpho-syntax }\end{array}$ & & $\begin{array}{l}\text { Partial: } 2 \\
\text { Missed: } 2\end{array}$ & & $\begin{array}{l}\text { Omission: } 1 \\
\text { Partial: } 2 \\
\text { Missed: } 1 \\
\text { Wrong: } 3 \\
\text { Quote: } 3\end{array}$ \\
\hline $\mathbf{L}$ & $\begin{array}{l}\text { Synonyms } \\
\text { Parapraph Picture } \\
\text { Paragraph Inferential } \\
\text { Morpho-syntax }\end{array}$ & & $\begin{array}{l}\text { Omission: } 2 \\
\text { Partial: } 1 \\
\text { Missed: } 1 \\
\text { Wrong: } 1 \\
\text { Quote: } 1\end{array}$ & & $\begin{array}{l}\text { Omission: } 5 \\
\text { Partial: } 1 \\
\text { Missed: } 1 \\
\text { Wrong: } 1 \\
\text { Quote: } 1 \\
\text { Other: } 2\end{array}$ \\
\hline$S$ & $\begin{array}{l}\text { Functional reading } \\
\text { Synonyms } \\
\text { Paragraph Picture } \\
\text { Morpho-syntax }\end{array}$ & $\begin{array}{l}\text { Oral reading } \\
90 \% \text { letter naming } \\
93 \% \text { word reading }\end{array}$ & Quote: 2 & $\begin{array}{l}\text { Wrong: } 1 \\
\text { Quote: } 1 \\
\text { Other: } 1\end{array}$ & $\begin{array}{l}\text { Omission: } 1 \\
\text { Partial: } 3 \\
\text { Missed: } 1 \\
\text { Quote: } 1 \\
\text { Other: } 1\end{array}$ \\
\hline
\end{tabular}


Meteyard, L., Bruce, C., Edmundson, A., \& Oakhill, J. (2014). Profiling text comprehension impairments in aphasia. Aphasiology, (aheadof-print), 1-28.

\begin{tabular}{|c|c|c|c|c|c|}
\hline $\mathbf{P}$ & $\begin{array}{l}\text { Paragraph Picture } \\
\text { Paragraph Factual } \\
\text { Paragraph Inferential } \\
\text { Morpho-syntax }\end{array}$ & $\begin{array}{l}\text { Oral reading } \\
0 \% \text { letter naming } \\
83 \% \text { word reading } \\
66 \% \text { sentence reading }\end{array}$ & $\begin{array}{l}\text { Partial: } 1 \\
\text { Wrong: } 1 \\
\text { Quote: } 1 \\
\text { Wrong: } 1\end{array}$ & $\begin{array}{l}\text { Missed: } 3 \\
\text { Quote: } 1 \\
\text { Wrong: } 1 \\
\text { Other: } 1\end{array}$ & $\begin{array}{l}\text { Omission: } 3 \\
\text { Partial: } 3 \\
\text { Missed: } 1 \\
\text { Wrong: } 3 \\
\text { Quote: } 2\end{array}$ \\
\hline Totals* & $\begin{array}{l}\text { Functional: } 2 / 4 \\
\text { Synonyms: } 2 / 4 \\
\text { Paragraph Picture: } 4 / 4 \\
\text { Paragraph Factual: } 1 / 4 \\
\text { Paragraph Inferential: } \\
\text { 3/4 } \\
\text { Morpho-syntax: } 4 / 4\end{array}$ & Oral reading: $2 / 4$ & $\begin{array}{l}\text { Omission: } 2(1 / 4) \\
\text { Partial: } 4(3 / 4) \\
\text { Missed: } 3(2 / 4) \\
\text { Wrong: } 2(2 / 4) \\
\text { Quote: } 4(3 / 4) \\
\text { Other: } 1(1 / 4)\end{array}$ & $\begin{array}{l}\text { Omission: } 0 \\
\text { Partial: } 0 \\
\text { Missed: } 3(1 / 4) \\
\text { Wrong: } 2(2 / 4) \\
\text { Quote: } 2(2 / 4) \\
\text { Other: } 2(2 / 4)\end{array}$ & $\begin{array}{l}\text { Omission: } 10(4 / 4) \\
\text { Partial: } 9(4 / 4) \\
\text { Missed: } 4(4 / 4) \\
\text { Wrong: } 7(3 / 4) \\
\text { Quote: } 7(4 / 4) \\
\text { Other: } 3(2 / 4)\end{array}$ \\
\hline
\end{tabular}

\footnotetext{
* For RCBA, number of patients with errors on those subtests. For MCLA, total number of errors in that category with number of patients in brackets.
} 
Meteyard, L., Bruce, C., Edmundson, A., \& Oakhill, J. (2014). Profiling text

comprehension impairments in aphasia. Aphasiology, (ahead-of-print), 1-28.

Appendix 2 Table 2: Errors on local and global inferencing

Correct answers received 1 point, partial answers received a score of 0.5 , all other errors were scored as 0.

\section{PT ID Question condition}

Local Global

\begin{tabular}{lll}
\hline W & $\begin{array}{l}\text { Partial: } 1 \\
\text { Other: } 1\end{array}$ & $\begin{array}{l}\text { Quote: } 1 \\
\text { Other: } 1\end{array}$ \\
& Partial: 1 & $\begin{array}{l}\text { Omission: } 1 \\
\text { Quote: } 2\end{array}$ \\
& & $\begin{array}{l}\text { Partial: } 1 \\
\text { Omission: } 1\end{array}$ \\
S & Omission: 1 & Partial: 3 \\
& & Wrong: 1 \\
& & Quote: 3 \\
P & & Wrong: 2 \\
Totals* & Qmission: $1(1 / 4)$ & Ouote: 3 \\
& Omission: $2(2 / 4)$ \\
& Partial: $2(2 / 4)$ & Partial: $4(2 / 4)$ \\
& Missed: 0 & Missed: 0 \\
& Wrong: $1(1 / 4)$ & Wrong: $3(2 / 4)$ \\
& Quote: $1(1 / 4)$ & Quote: $9(4 / 4)$ \\
& Other: $1(1 / 4)$ & Other: $1(1 / 4)$
\end{tabular}

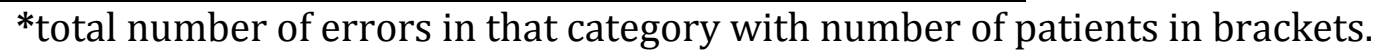


Meteyard, L., Bruce, C., Edmundson, A., \& Oakhill, J. (2014). Profiling text

comprehension impairments in aphasia. Aphasiology, (ahead-of-print), 1-28.

Appendix 2 Table 3: Responses for sentence verification: items accepted as 'old'

PT ID Sentence verification sentence type

Meaning the same Meaning different

\begin{tabular}{lllll} 
& $\begin{array}{l}\text { Original } \\
(/ 3)\end{array}$ & $\begin{array}{l}\text { Paraphrase } \\
(/ 4)\end{array}$ & $\begin{array}{l}\text { Meaning } \\
\text { Change } \\
(/ 5)\end{array}$ & $\begin{array}{l}\text { Distracter } \\
(/ 3)\end{array}$ \\
\hline $\mathbf{W}$ & 3 & 3 & 2 & 0 \\
$\mathbf{L}$ & 2 & 4 & 3 & 0 \\
$\mathbf{S}$ & 3 & 3 & 1 & 2 \\
$\mathbf{P}$ & 3 & 3 & 1 & 1 \\
\hline
\end{tabular}

Appendix 2 Table 4: Responses for error detection tasks

Responses are broken down into correct detections (correctly identifying errors in the text) and false positives (incorrectly finding errors where there are none).

PT ID Error detection condition and response

Easy Hard

\begin{tabular}{lllll} 
& $\begin{array}{l}\text { Correct } \\
\text { detection } \\
(/ 4)\end{array}$ & $\begin{array}{l}\text { False } \\
\text { positive } \\
(/ 2)\end{array}$ & $\begin{array}{l}\text { Correct } \\
\text { detection } \\
(/ 6)\end{array}$ & $\begin{array}{l}\text { False } \\
\text { positive } \\
(/ 2)\end{array}$ \\
\hline W & 4 & 0 & 6 & 0 \\
L & 2 & 1 & 2 & 0 \\
S & 4 & 0 & 4 & 0 \\
P & 5 & 0 & & n/a \\
\hline
\end{tabular}

